\title{
The Effects of Ultrasound-guided and Anatomic landmark-based Superficial Cervical Plexus Block on Post-operative Pain Intensity in Thyroidectomy Patients: A Clinical Trial
}

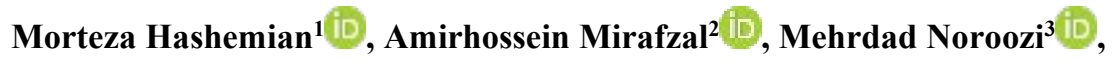 \\ Majid Kazemi ${ }^{4}$ (D), Sadra Samadi ${ }^{*}$ (iD) \\ 1. Dept. of Anesthesiology and Pain Medicine, Kerman University of Medical Sciences, Kerman, Iran \\ 2. Dept. of Emergency Medicine, Kerman University of Medical Sciences, Kerman, Iran \\ 3. Dept. of Anesthesiology, Isfahan University of Medical Sciences, Isfahan, Iran \\ 4. Medical Surgical Nursing Dept, Nursing and Midwifery faculty, Non-Communicable Diseases Research \\ Center, Rafsanjan University of Medical Sciences, Rafsanjan, Iran
}

\begin{tabular}{|c|}
\hline Article Info \\
\hline doi $10.30699 /$ jambs.29.137.125 \\
\hline $\begin{array}{l}\text { Received: 2020/11/14; } \\
\text { Accepted: 2021/05/07; } \\
\text { Published Online: 01 Aug 2021; }\end{array}$ \\
\hline $\begin{array}{l}\text { Use your device to scan and read the } \\
\text { article online }\end{array}$ \\
\hline 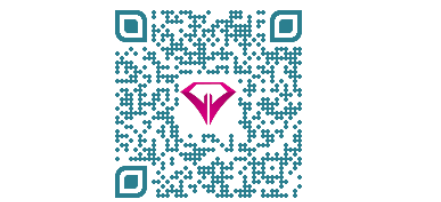 \\
\hline
\end{tabular}

Corresponding Information: Sadra Samadi,

Dept. of Anesthesiology and Pain Medicine, Bahonar Hospital, Gharani St., Kerman, Iran

E-Mail: : Samadisadra@yahoo.com

\section{ABSTRACT}

Background \& Objective: Pain is one of the most common complications after thyroidectomy. Opioid administration can overcome this complication, however, it has some side effects, including nausea and vomiting. So, the use of local anesthetic instead of opioids is a good alternative. This study was conducted to evaluate and compare the effect of ultrasound-guided superficial cervical plexus block (SCPB) versus anatomic landmark (LM)-based SCPB on post-operative severity of pain after thyroidectomy.

Materials \& Methods: In this clinical trial 113 patients were selected through convenience sampling method. Patients were randomly divided in to three groups: a) control, b) LM-based nerve block, and c) ultrasound-guided nerve block. Data collection was performed by demographic checklist and visual analogue scale (VAS). After general anesthesia, nerve block was performed by $15 \mathrm{~mL}$ of $0.25 \%$ Bupivacaine solution. Postoperative pain was measured in post anesthesia care unit (PACU) at 3, 6, 9, 12 and 24 hours. One-way analysis of variance (ANOVA), chi-square and fisher exact tests and repeated measurements were used for data analysis (SPSS V.18 software).

Results: Patients of group $\mathrm{c}$ in comparison to other groups received lower analgesic dose during operation $(\mathrm{p} \leq 0.001)$; fewer of them needed post-operative analgesia $(\mathrm{p} \leq 0.001)$. The ultrasound-guided SCPB group had significantly lower pain severity in comparison to other groups in different time intervals $(\mathrm{p} \leq 0.001)$.

Conclusion: Ultrasound-guided superficial cervical plexus block reduced the pain after thyroidectomy. However, the ultrasound-guided nerve block is a wellorganized and expanding technique, but it needs more practice and training.

Keywords: Superficial cervical plexus block, Thyroidectomy, Pain intensity, Landmark (LM), Ultrasound

\section{Introduction}

Thyroid disorders are some of the most common endocrine diseases with $5-20 \%$ of prevalence in the US (1); they may lead to thyroidectomy as a therapeutic approach for variety of reasons (2). Within 24 hours after thyroidectomy, patients usually experience mild to moderate pain. Surgical procedures or general anesthesia cause experiencing difficulty swallowing, sore throat, nausea and vomiting. To prevent these symptoms, some actions including prescribing opioids and nonsteroidal anti-inflammatory drugs, local or regional anesthesia have been done (3).

Superficial cervical plexus block (SCPB) is one of the ways to reduce pain after thyroidectomy (4); the ability to continuously monitor the neurological vigilant is one of the advantages of this anesthesia technique for subsequent actions, leading to a significant increase in the acceptability of the technique (5). The ultrasound guidance or the conventional landmark (LM) technique can simplify the 
procedures (6). Precise needle guideline, possibility of control the spread of local anesthesia during injection, a lower risk of toxicity with local anesthesia, increased speed and fine-tuning of work and success in blocking the area are among the benefits of ultrasound-guided regional anesthesia (6-8).

Several studies showed that preoperative ultrasoundguided bilateral SCPB will elevate the quality of recuperation, reduction of postoperative pain and patient satisfaction in thyroid surgery $(9,10)$. Similarly, based on some studies, ultrasound-guidance for supraclavicular brachial plexus block is beneficial to determine the exact location of the nerve and minimize the number of needles inserted without serious complications (11); also it improves the efficacy and safety of procedure. Several studies have shown, that it can reduce the block performance time and the number of needle traversing; it also shortens the block onset time (6-8). Senapathi et al. in their study showed that ultrasound-guided bilateral SCPB was more efficient to reduce the intra- and postoperative pain in patients undergoing thyroidectomy in comparison to LM technique (12).

Therefore, regional techniques may help to reduce postoperative pain and the need for systemic analgesia; ultrasound-guidance can help to performe it better, improve the quality of recovery and reduce the number of patients requiring analgesia (9). The key role of nerve block in preemptive analgesia is evident; it is of paramount significance in management all types of post-operative pain. The ultrasound-guided nerve block has gained more popularity in well-equipped centers recently. On the other hand, all operation rooms are not equipped with ultrasound facilities in low income countries. Thus this study was conducted to see whether ultrasound-guided SCPB has any significant difference with LM block on post thyroidectomy pain intensity or not?

\section{Materials and Methods}

This clinical trial (Registry number: IRCT201906110$43861 \mathrm{~N} 1)$ was conducted among candidate patients for thyroid surgery, who referred to Shahid Bahonar hospital, Kerman, 2019. The inclusion criteria were as follows: age 18-65 years, ASA class less than II, no history of thyroid diseases and parathyroid and neck surgery, absence of retrosternal goiter, no thyroid dysfunction, no emergency re-surgery in the first 24 hours, body mass index less than 25 , no coagulation abnormalities, no short neck, no pathology at the injection site, no neck lymph node dissection surgical incision length less than $6 \mathrm{~cm}$.

Exclusion criteria were surgery duration more than 120 minutes, true allergy to Bupivacaine, opioid addiction and patient refusal. Convenience sampling method was used for patient selection. Patients were randomly divided into three groups using random allocation sequence: (a) no nerve block (control), (b) LM-based nerve block and (c) ultrasound-guided nerve block. After interventions, 39 patients in the ultrasound-guided nerve block group, 35 patients in the LM-based nerve block group, and 39 in the control group were remained.

\section{General anesthesia procedure}

After conducting general anesthesia for the patient, the nerve block process began. Vital parameters including heart rate, blood pressure and oxygen saturation level were monitored. For premedication, $1 \mathrm{mg}$ of Midazolam and Fentanyl ( $2 \mu \mathrm{g} \mathrm{kg}-1)$ were prescribed intravenously; general anesthesia was performed using Propofol (2-3 mg kg-1). Then, Atracurium (0.5 mg kg-1) was administered for endotracheal intubation, using a 7-mm internal diameter wire reinforced tube.

Maintenance of general anesthesia was performed with Isoflurane ( $1 \%-1.2 \%)$ and oxygen-nitrous oxide mixture (40-60\%). Additional doses of Fentanyl (1 $\mu \mathrm{kg}-1)$ were administered in the event of increased heart rate or systolic blood pressure greater than $20 \%$ of preoperative values. The superficial cervical plexus block was performed by a senior resident of anesthesiology, familiar with the block under the direct supervision of the pain fellowship.

\section{LM-based nerve block}

We turned the patient's head to the opposite side of the block side and identified the sternocleidomastoid (SCM) muscle. The needle insertion site was the midline of the mastoid and transverse process of the sixth cervical vertebra parallel to the latter edge of the clavicular head of the SCM muscle. After Prep, the needle was inserted from the posterior edge of the SCM and three 5-mL FanShaped of $0.25 \%$ Bupivacaine solution were injected into the subcutaneous, by vertical and cephalad manner (totally, $15 \mathrm{~mL}$ ). The injection depth was not greater than $1-2 \mathrm{~cm}$, to prevent phrenic and recurrent laryngeal nerve block, as well as intrathecal and intervertebral artery injection. Laryngoscopy was performed before and after surgery to evaluate laryngeal nerve palsy.

\section{Ultra-sound guided nerve block}

We used linear probe (6-15 MHz frequency) of sonosite as nerve ultrasound machine to see the plexus at the depth of 1-2 cm. After Prep, as the same position as LM group, the transducer was placed on the middle part of the SCM muscle (approximately parallel to the cricoid cartilage). After visualizing the SCM muscle, transducer was moved to the posterior edge of the muscle in the middle of the monitor. In this case, we searched for the brachial plexus and interscalene groove.

The plexus is seen as a condensation of small hypoechoic nodules (honeycomb view) immediately below the prevertebral fascia (overlying the interscalene groove). After visualizing the plexus, a 2.5 -inch $25 \mathrm{G}$ needle was inserted and placed in adjacent to the plexus. After negative aspiration, $1-2 \mathrm{~mL}$ of $0.25 \%$ Bupivacaine was injected to ensure proper injection site. The residual local anesthetic was then injected (15 mL totally). If the injection did not result in a proper local anesthetic distri- 
bution, the needle was relocated and injected to achieve the appropriate local anesthetic distribution.

\section{Pain intensity evaluation}

Before any intervention, individuals in all groups were explained face-to-face adequately on how to express visual analogue scale(VAS). VAS is the most widely used pain assessment tool in the world, because of its ease of use. This is a $10-\mathrm{cm}$ scale, whose left side (number 0 ) indicates no pain and right side (number 10) indicates the most severe pain. Mild pain is characterized by a score of 1-3; the score 4-7 indicates moderate pain, and 8-10 reveals severe pain. The postoperative pain was measured in the post anesthesia care unit (PACU) at 3, 6, 9, 12 and 24 hours. If the patient's pain was moderate or severe, 0.1 mg kg-1 of intravenous Morphine was administered to the patient; the total dose of received Morphine was recorded within 24 hours. It should be noted that the patient and the pain assessor were unaware of the blockage type.

\section{Data collection}

A demographic checklist including age, sex, comorbidity history, addiction history, type and amount of analgesia, as well as VAS were used for data collection.

\section{Ethical approval}

The protocol of present study reviewed and approved by the Ethics Committee of Kerman University of Medical Sciences (Ethic number: IR.KMU.REC.1398.-
135). Before any interventions, the aims were described for patients and written informed consent was taken.

\section{Statistical analysis}

Data were described using mean $( \pm$ Standard Deviation (SD)). The Kolmogorov-Smirnov test was used for data normality assessment. One-way analysis of variance (ANOVA), chi-square and fisher exact tests and repeated measurements were used for comparison the demographic and clinical characteristics and also patients`complications. Tukey's post hoc test was used for pairwise comparison of pain intensity between groups. The significance level of the tests was $p<0.05$. The Statistical Package for the Social Sciences (SPSS) version 18 was used for data analysis.

\section{Results}

\section{Baseline characteristics of subjects}

According to the findings, 113 patients participated in the present study with the mean age of $37.45 \pm 4.49$ years (range: $28-48$ years). Of these, $94(83.2 \%)$ were female and $19(16.8 \%)$ were male. Moreover, $12(10.6 \%)$ had a history of smoking. The results showed that the three groups did not differ in the mean age $(\mathrm{p}=0.758)$, gender $(p=0.56)$, history of the comorbid diseases $(p=0.38)$ and addiction history $(\mathrm{P}=0.09)$ (Table 1$)$.

Table 1. Demographic and clinical characteristics of patients

\begin{tabular}{|c|c|c|c|c|c|c|}
\hline \multicolumn{2}{|c|}{ Variables } & Total subject & $\begin{array}{l}\text { Ultrasound- } \\
\text { guided }\end{array}$ & $\begin{array}{l}\text { Landmark } \\
\text { group }\end{array}$ & Control group & P-value \\
\hline \multicolumn{2}{|c|}{ Age } & $37.45 \pm 4.49$ & $37.51 \pm 3.50$ & $37.82 \pm 5.52$ & $37.05 \pm 4.40$ & 0.27 \\
\hline \multirow{2}{*}{ Gender } & Male & 19 & $7(36.8 \%)$ & $4(21.1 \%)$ & $8(42.1 \%)$ & \multirow{2}{*}{0.56} \\
\hline & Female & 94 & $32(34.1 \%)$ & $31(32.9 \%)$ & $31(32.9 \%)$ & \\
\hline \multirow{2}{*}{ Comorbidity } & Negative & 81 & $31(38.4 \%)$ & $23(28.3 \%)$ & $27(33.3 \%)$ & \multirow{2}{*}{0.38} \\
\hline & Positive & 32 & $8(25 \%)$ & $12(37.5 \%)$ & $12(37.5 \%)$ & \\
\hline \multirow{2}{*}{$\begin{array}{l}\text { Cigarette } \\
\text { smoking }\end{array}$} & Negative & 101 & $38(37.6 \%)$ & $29(28.7 \%)$ & $34(33.7 \%)$ & \multirow{2}{*}{0.09} \\
\hline & Positive & 12 & $1(8.3 \%)$ & $6(50 \%)$ & $5(41.7 \%)$ & \\
\hline
\end{tabular}

\section{Post-operative analgesia requirements}

As shown in table 2 , the number of patients received Fentanyl during operation was not significantly different $(\mathrm{P}=0.08)$, but the total Fentanyl dose was remarkably lower among patients in ultra-sound group $(\mathrm{P} \leq 0.001)$; fewer of them needed post-operative Morphine in comparison to other patients $(\mathrm{P} \leq 0.001)$. The total Morphine dose in post-operative period was similar between the groups $(\mathrm{P}=0.06)$. There was no difference in postoperative nausea and vomiting and postoperative dyspnea $(\mathrm{P}=0.27$ and $\mathrm{P}=0.86$, respectively). The status of vocal cord in majority of patients was normal regardless of intervention $(\mathrm{P}=0.51)$ (Table 2).

\section{Pain intensity}

Our findings showed that there was a significant difference for severity of pain between the all groups of ultrasound-guided nerve block, LM-based nerve block and control. The pain severity in the ultrasound-guided nerve block group was significantly lower in comparison to other two groups in all time intervals after surgery $(p<0.001)$ (Table 3). However, the pain severity in the LM-based nerve block group was not different in the control group at all-time intervals after operation ( $>0.05$ ); there was no significant difference in the pain severity for patients in each group (ultrasound-guide, LM and control group) during different time intervals $(\mathrm{P}=0.75$, 0.81 and 0.22 , respectively) 
Table 2. Clinical characteristics and complications after surgery in patients

\begin{tabular}{|c|c|c|c|c|c|c|}
\hline \multicolumn{2}{|c|}{ Variables } & Total & $\begin{array}{l}\text { ultrasound- } \\
\text { guided }\end{array}$ & $\begin{array}{l}\text { Landmark } \\
\text { group }\end{array}$ & Control group & P-value \\
\hline \multirow{2}{*}{$\begin{array}{l}\text { Received } \\
\text { Fentanyl } \\
\text { during } \\
\text { operation }\end{array}$} & Negative & 20 & $9(45 \%)$ & $2(10 \%)$ & $9(45 \%)$ & \multirow[b]{2}{*}{0.08} \\
\hline & Positive & 93 & $30(32.3 \%)$ & $33(35.4 \%)$ & $30(32.3 \%)$ & \\
\hline \multicolumn{2}{|c|}{$\begin{array}{l}\text { Total Fentanyl dose } \\
\text { received during } \\
\text { operation (mean } \pm \text { SD) }\end{array}$} & $76.90 \pm 52.70$ & $44.16 \pm 39.76$ & $84.37 \pm 42.95$ & $101.66 \pm 57.95$ & $<0.001$ \\
\hline \multirow{2}{*}{$\begin{array}{l}\text { Received } \\
\text { Morphine } \\
\text { after } \\
\text { operation }\end{array}$} & Negative & 38 & $22(57.8 \%)$ & $7(18.6 \%)$ & $9(23.6 \%)$ & \multirow[b]{2}{*}{$<0.001$} \\
\hline & Positive & 75 & $17(22.7 \%)$ & $28(37.3 \%)$ & $30(40 \%)$ & \\
\hline \multicolumn{2}{|c|}{$\begin{array}{l}\text { Total Morphine dose } \\
\text { received after operation } \\
(\text { mean } \pm \text { SD })\end{array}$} & $5.37 \pm 1.03$ & $5.29 \pm 1.21$ & 5 & $5.83 \pm 1.89$ & 0.06 \\
\hline \multirow{2}{*}{$\begin{array}{l}\text { Nausea } \\
\text { and } \\
\text { vomiting }\end{array}$} & Negative & 101 & $37(36.6 \%)$ & $29(28.7 \%)$ & $35(34.7 \%)$ & \multirow{2}{*}{0.27} \\
\hline & Positive & 12 & $2(16.6 \%)$ & $6(50 \%)$ & $4(33.4 \%)$ & \\
\hline \multirow{2}{*}{ Dyspnea } & Negative & 108 & $38(35.2 \%)$ & $33(30.5 \%)$ & $37(34.3 \%)$ & \multirow{2}{*}{0.86} \\
\hline & Positive & 5 & $1(20 \%)$ & $2(40 \%)$ & $2(40 \%)$ & \\
\hline \multirow{2}{*}{$\begin{array}{c}\text { Status of } \\
\text { vocal cords }\end{array}$} & $\begin{array}{l}\text { Normal } \\
\text { (healthy) }\end{array}$ & 107 & $38(35.5 \%)$ & $32(30 \%)$ & $37(34.5 \%)$ & \multirow[t]{2}{*}{0.51} \\
\hline & Defective & 6 & $1(16.6 \%)$ & $3(50)$ & $2(33.4 \%)$ & \\
\hline
\end{tabular}

Table 3. The comparison of pain intensity $(\operatorname{mean} \pm \mathrm{SD})$ during 6 time intervals within and between the groups

\begin{tabular}{|c|c|c|c|c|}
\hline Time intervals & $\begin{array}{l}\text { Ultrasound- } \\
\text { guided }\end{array}$ & Landmark group & Control group & P-value \\
\hline After surgery & $2.1 \pm 61.11$ & $4.1 \pm 20.10$ & $4.0 \pm 28.99$ & $<0.001 *$ \\
\hline 3 hours & $2.0 \pm 78.95$ & $4.0 \pm 82.85$ & $4.0 \pm 74.90$ & $<0.001 *$ \\
\hline 6 hours & $2.1 \pm 56.02$ & $4.1 \pm 71.44$ & $4.1 \pm 71.27$ & $<0.001 *$ \\
\hline 9 hours & $2.1 \pm 74.14$ & $4.0 \pm 82.98$ & $4.1 \pm 74.04$ & $<0.001^{*}$ \\
\hline 12 hours & $2.1 \pm 76.06$ & $4.1 \pm 82.01$ & $4.1 \pm 66.05$ & $<0.001 *$ \\
\hline 1 day & $2.0 \pm 66.98$ & $4.1 \pm 42.15$ & $4.1 \pm 28.02$ & $<0.001 *$ \\
\hline P-value & $0.75 * *$ & $0.81 * *$ & $0.22 * *$ & --- \\
\hline
\end{tabular}

*ANOVA p-value

$* *$ Freedman p-value

\section{Discussion}

The present study aimed to evaluate the effect of ultrasound-guided SCPB on pain intensity after thyroid surgery compared to anatomic LM-based SCPB. The results of the present study showed a significant difference between all groups for pain severity. Also, receiving sedative agents during and after operation were statistically different between the three groups and in both situations; patients in ultrasound-guided nerve block group received lower sedation agents $(8,9)$.
The results of the present research revealed that severity of pain was significantly different between the three groups under the study at all-time points. The pain severity was lower in the ultrasound-guided nerve block group and LM-based nerve block group than the control, at different measurement times. On the other hand, the pain severity of the ultrasound-guided nerve block group was also lower than the LM-based nerve block group. A Sohoni and colleagues also reported 
similar conclusions. They demonstrated that Ultrasound-guided forearm nerve blocks, was more effective for hand anesthesia than traditional anatomic LMbased wrist blocks (13).

Senapathi et al. showed that intra and postoperative pain at thyroidectomy of the ultrasound-guided nerve block group was less than the LM-based nerve block group (12). AEA Elmaddawy and colleagues found that sonographic-guided bilateral SCPB in combination with Bupivacaine, Dexmedetomidine, and Epinephrine was superior to Bupivacaine for long-term analgesia with less intra- and postoperative opioid consumption; it was also associated with lower side effects profile during thyroid surgery (10). In this way, it seems that less manipulation is associated with less damage to the surrounding tissues.

Ultrasound-guidance in clinical processes such as brachial plexus block has become popular. This method has been considered to be an effective method with real-time visualization (14). The findings of a study by NS Sandhu and colleagues indicated that the ultrasound use can allow accurate deposition of local anesthetic perineurally; it may decrease the complications of infraclavicular brachial plexus block (15). PA Vieira also showed that the addition of Dexamethasone to a interscalene block by Bupivacaine-EpinephrineClonidine, prolongs sensory block and reduces the opioid use (16).

The use of ultrasound in performing regional anesthetic procedures is rapidly expanding. Successful and reliable implementation of ultrasound-guided peripheral nerve block requires the use of appropriate imaging and diagnosis of the desired nerves, skill in simultaneous needle guidance and evaluation the drug distribution at the appropriate site. One of the most important benefits of ultrasound is the reduction of block-related complications; there are various reports of block side effects. Auroy et al. estimated the probability of neural defects in ultrasound-guided blocks to be $0.002 \%$ (17). Chan and Bigeleisen also noted an increase in nerve diameter following intramural injection $(18,19)$. In these studies, it should be noted that the injection cessation prevented neurological complications.

Ultrasound has other benefits, including reducing the likelihood of failure and decreasing the minimum drug dose $(7,20,21)$. Intra-tissue injection creates a hypoechoic image, whose diffusion site can be exhibited by the ultrasound. Therefore, the drug can be injected precisely at the desired site using ultrasound. In addition, intravascular injection and dissemination are also prevented and the likelihood of local anesthetics systemic toxicity reduces. It is important to mention, that failure is one of the major complications of the nerve block. The prevalence of block failure has been reported up to $20 \%$ in some reports (7).

Ultrasound guidance gives a slight improvement in block onset and the quality of peripheral nerve blocks, especially for the lower extremity. Sonographic visualization of the peripheral nerve and surrounding anatomy can provide valuable information for diagnostic purposes and method enhancement (21). The ultrasound also has limitations; with increasing depth, image quality reduces and needle guidance becomes more difficult. Images of tissues beyond the hyperechoic tissue (such as bone) are not visible. Visualization of small nerves is very difficult in depth, although superficial nerves such as ilioinguinal are easily recognizable (7).

\section{Conclusion}

According to the results of this study, it can be concluded that the ultrasound-guided superficial cervical plexus block reduced the pain after thyroidectomy. However, the ultrasound-guided nerve block is an efficient and expanding method, but it needs more practice and training.

\section{Acknowledgments}

The authors acknowledge the Kerman University of Medical Sciences, and thank who contributed for data collection, especially participating students.

\section{Conflict of Interest}

The authors have no conflict of interest to declare.

\section{Funding}

The authors did not receive any funding.

\section{References}

1. Dunn JT. Guarding our nation's thyroid health. J Clin Endocrinol Metab. 2002;87(2):486-8. [DOI:10.1210/jc.87.2.486]

2. Clark OH, Duh QY, Kebebew E. Textbook of endocrine surgery: JP Medical Ltd; 2016.

3. Shih ML, Duh QY, Hsieh CB, et al. Bilateral superficial cervical plexus block combined with general anesthesia administered in thyroid operations. World J Surg. 2010;34(10):2338-43. [DOI:10.1007/s00268-010-0698-7]

4. Wang $\mathrm{Q}, \mathrm{Li} \mathrm{Z}, \mathrm{Xu} \mathrm{S}$, et al. Feasibility of ultrasound-guided capsule-sheath space block combined with anterior cervical cutaneous nerves block for thyroidectomy: an observational pilot study. BMC Anesthesiol. 2015;15(1):4. [DOI:10.1186/1471-2253-15-4]

5. Halaszynski TM, Tom M. Ultrasound-guided peripheral nerve blocks. Basic Clinical 
Anesthesia: Springer; 2015. p. 253-63. [DOI:10.1007/978-1-4939-1737-2_23]

6. Marhofer P, Chan VW. Ultrasound-guided regional anesthesia: current concepts and future trends. Anesthesia \& Analgesia. 2007;104(5):1265-9.

[DOI:10.1213/01.ane.0000260614.32794.7b]

7. Willschke $\mathrm{H}$, Marhofer $\mathrm{P}$, Bösenberg A, et al. Ultrasonography for ilioinguinal/iliohypogastric nerve blocks in children. $\mathrm{Br} \mathrm{J}$ Anaesthesia. 2005;95(2):226-30. [DOI:10.1093/bja/aei157]

8. Koscielniak-Nielsen Z. Ultrasound-guided peripheral nerve blocks: what are the benefits? Acta Anaesthesiologica Scandinavica. 2008;52(6):727-37. [DOI:10.1111/j.13996576.2008.01666.x]

9. Yao Y, Lin C, He Q, Gao H, Jin L, Zheng X. Ultrasound-guided bilateral superficial cervical plexus blocks enhance the quality of recovery in patients undergoing thyroid cancer surgery: A randomized controlled trial. J Clin Anesthesia. 2020;61:109651.

[DOI:10.1016/j.jclinane.2019.109651]

10. Elmaddawy AEA, Mazy AE. Ultrasound-guided bilateral superficial cervical plexus block for thyroid surgery: The effect of dexmedetomidine addition to bupivacaine-epinephrine. Saudi J Anaesthesia. 2018;12(3):412. [DOI:10.4103/sja.SJA 653 17]

11. HR A. Ultrasound-guided brachial plexus block: a study on 30 patients. Tehran University Medical Journal TUMS Publications. 2009;67(2):151-7.

12. Senapathi TGA, Widnyana IMG, Aribawa IGNM, et al. Ultrasound-guided bilateral superficial cervical plexus block is more effective than landmark technique for reducing pain from thyroidectomy. J Pain Res. 2017;10:1619. [DOI:10.2147/JPR.S138222]

13. Sohoni A, Nagdev A, Takhar S, Stone M. Forearm ultrasound-guided nerve blocks vs landmark-based wrist blocks for hand anesthesia in healthy volunteers. Am J Emerg Med.
2016;34(4):730-4.

[DOI:10.1016/j.ajem.2016.01.020]

14. Entezari S, Mohsenpour AM, Imani F, Alebouyeh M, Zafarghandi M. Supraclavicular block with sonography alone or combined with nerve-stimulation: Which one is more effective? 2013;3(4):229-34.

15. Sandhu N, Capan L. Ultrasound-guided infraclavicular brachial plexus block. $\mathrm{Br} \mathrm{J}$ Anaesthesia. 2002;89(2):254-9. [DOI:10.1093/bja/aef186]

16. Vieira PA, Pulai I, Tsao GC, Manikantan P, Keller B, Connelly NR. Dexamethasone with bupivacaine increases duration of analgesia in ultrasound-guided interscalene brachial plexus blockade. Europ J Anaesthesiol. 2010;27(3):2858. [DOI:10.1097/EJA.0b013e3283350c38]

17. Auroy Y, Benhamou D, Bargues L, et al. Major complications of regional anesthesia in France.The SOS Regional Anesthesia Hotline Service. Anesthesiology 2002;97(5):1274-80. [DOI:10.1097/00000542-200211000-00034]

18. Bigeleisen P, Wilson M. A comparison of two techniques for ultrasound guided infraclavicular block. Br J Anaesth. 2006;96(4):502-7. [DOI:10.1093/bja/ael024]

19. Schafhalter-Zoppoth I, Zeitz ID, Gray A. Ultrasound evidence of intraneural injection. Anesthesia \& Analgesia. 2005;101(2):611. [DOI:10.1213/01.ANE.0000159011.02691.23]

20. Marhofer P, Schrögendorfer $\mathrm{K}$, Wallner $\mathrm{T}$, Koinig H, Mayer N, Kapral S. Ultrasonographic guidance reduces the amount of local anesthetic for 3-in-1 blocks. Reg Anesthesia Pain Medicine. 1998;23(6):584-8. [DOI:10.1097/00115550199823060-00013]

21. Hashemi SM, Akhyani V, Dadkhah P, Jalili P, Poorfarokh M, Saafi E. Evaluation of diagnostic accuracy of sacroiliac joint block under sonographic guidance in low back and pelvic pain. Neurosci J Shefaye Khatam. 2014;2(2):3140 . [DOI:10.18869/acadpub.shefa.2.2.31]

\section{How to Cite This Article:}

Hashemian M, Mirafzal A, Noroozi M, Kazemi M, Samadi S. The Effects of Ultrasound-guided and Anatomic landmark-based Superficial Cervical Plexus Block on Post-operative Pain Intensity in Thyroidectomy Patients: A Clinical Trial. J Adv Med Biomed Res. 2021; 29 (137): 346-351

\section{Download citation:}

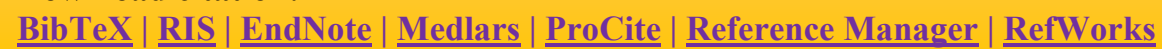

\section{Send citation to:}
(3) Mendeley 